\title{
EFFECTS OF CENTRALLY AFFECTING DRUGS ON THE DIURETIC AND ANTIDIURETIC ACTIONS OF INTRACEREBROVENTRICULAR PROSTAGLANDIN $\mathrm{E}_{2}$
}

\author{
Seigo FUJIMOTO and Shiro HISADA \\ Department of Pharmacology, Nagoya City University Medical School, \\ Mizuho-ku, Nagoya 467, Japan
}

Accepted August 29, 1977

\begin{abstract}
Effects of centrally affecting drugs on the diuretic and antidiuretic actions of intracerebroventricularly (i.c.v.) injected prostaglandin ( $P G$ ) $E_{2}$ in ethanol-anaesthetized rats were studied. $\mathrm{PGE}_{2}$, when injected i.c.v. at a dose of 1 nmole, produced diuresis followed by antidiuresis. When morphine $(0.1 \mathrm{mM})$ was perfused i.c.v., urine outflow decreased and neither diuretic nor antidiuretic effects of i.c.v. $\mathrm{PGE}_{2}$ was apparcnt. The perfusions with picrotoxin, $\gamma$-aminobutyric acid and L-glutamate inhibited either the diuretic or the antidiuretic effect of $\mathrm{PGE}_{2}$. On the other hand, when pentobarbital, diazepam, isoniazid and strychnine were perfused i.c.v., the diuretic action of $\mathrm{PGE}_{2}$ was diminished and antidiuresis in response to $\mathrm{PGE}_{2}$ remained unchanged. These results suggested that the diuretic and antidiuretic effects of $\mathrm{PGE}_{2}$ could be separated. The development of the diuretic effect of $\mathrm{PGE}_{2}$ was completely blocked by amitriptyline and antidiuresis was increased. In rats pretreated i.c.v. with reserpine, the diuretic effect of $\mathrm{PGE}_{2}$ was prolonged and antidiuresis in response to $\mathrm{PGE}_{2}$ was not observed. An antidiuretic action of i.c.v. norepinephrine was not yaried by reserpine. Mechanisms for both effects of $\mathrm{PGE}_{2}$ are discussed.
\end{abstract}

Prostaglandins (PGs) are present in most parts of the brain including the hypothalamus $(1,2)$, and readily released from the central nervous system (CNS) both spontaneously and by electric or chemical stimulation (3). In addition, since PGs could be detected in effluents of the perfused lateral ventricle (4) and superfusates of the cerebral cortex $(5,6)$, they may be naturally-occurring components in the cerebrospinal fluid.

Hedge (7) was of the opinion that hypothalamic and pituitary PGs regulated anterior pituitary hormone secretion. On the other hand, regarding with posterior pituitary hormone secretion, $\mathrm{PGF}_{2 \alpha}$ was suggested to inhibit milk ejection by a central block on oxytocin release (8). $P G E_{1}$ injected centrally, inhibited water diuresis (9) and increased urinary concentrations of $\mathrm{ADH}(10)$. It was shown that central $\mathrm{PGE}_{2}$ increased plasma $\mathrm{ADH}$ contents (11) and caused diuresis followed by antidiuresis (12). PGA 2 injected intracerebroventricularly (i.c.v.), decreased urine outflow in some of ethanol-anaesthetized rats or increased it in others (13). Thus, it is likely that at least $E_{1}, E_{2}$ and $A_{2}$ of the PGs act on the CNS to regulate water metabolisnn.

Chemicals known to inhibit some effects of the PGs, will be good tools to study mechanisms of the effects of the PGs. For instance, Peng et al. (14) who demonstrated that i.p.

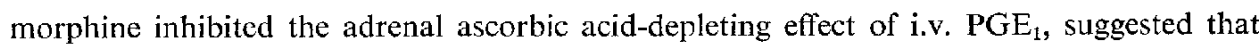
the action of $\mathrm{PGE}_{1}$ on $\mathrm{ACTH}$ release was at some level in the CNS. Such was later con- 
firmed by Hedge and Hanson (15) who reported that ACTH-releasing action of $\mathrm{PGE}_{1}$ injected into the median eminence was abolished by i.p. morphine.

The febrile response to central $\mathrm{PGE}_{1}$ was attenuated in rabbits pretreated centrally with 6-hydroxydopamine (16) and the present authors showed that i.c.v. perfusion with picrotoxin reduced the febrile action of i.c.v. $\mathrm{PGE}_{2}$ in rats (17). Fujimoto (18), furthermore, reported that although the potency of i.v. $\mathrm{PGA}_{2}$ as a vasodepressor in rats was significantly varied by some anaesthetics, the decrease in blood pressure by i.c.v. PGA $\mathrm{A}_{2}$ was not altered by these drugs.

In this work, therefore, an attempt was made to determine whether or not centrally affecting drugs could change the diuretic and antidiuretic effects of i.c.v. $\mathrm{PGE}_{2}$.

\section{MATERIALS AND METHODS}

As described previously (19), an artificial cerebrospinal fluid (CSF) was perfused from the lateral ventricle to the cerebral aquaeduct of ethanol-anaesthetized rats. The perfusion rate was $10 \mu 1 / \mathrm{min}$. Three \% ethanol was additionally infused i.v. at a rate of $0.1 \mathrm{ml} / \mathrm{min}$ to maintain anaesthesis and diuresis. Urine was collected through a bladder cannula and the rate of urine outflow was recorded by a photoelectric drop counter. Results were expressed as a percentage of change by drugs in urine outflow and control values (expressed as $100 \%$ of urine outflow ranged from $0.8 \mathrm{ml} / 10 \mathrm{~min}$ to $1.2 \mathrm{ml} / 10 \mathrm{~min}$.

$\mathrm{PGE}_{2}$ (Ono Pharmaceutical Co., Ltd, Osaka) was injected at a volume of $10 \mu$ through a lateral ventricular cannula. This PG was dissolved immediately before use by ethanol and diluted by the CSF. Ethanol concentration of an original $\mathrm{PGE}_{2}$ solution (10 nmoles/ $10 \mu 1)$ was $3 \%$.

In some experiments, reserpine (Apoplon, Daiichi Seiyaku Co., Ltd., Tokyo) was injected i.c.v. at a dose of 49 nmoles, $24 \mathrm{hr}$ before the i.c.v. perfusion study was carried out.

Morphine sulfate, pentobarbital sodium, diazepam, isoniazid, strychnine nitrate, picrotoxin, amitriptyline hydrochloride, $\gamma$-aminobutyric acid (GABA), L-sodium glutamate (L-GA) and 1-norepinephrine bitartrate were dissolved by the CSF.

\section{RESULTS}

The i.c.v. injection of $0.3 \%$ ethanol did not change urine outflow.

When $\mathrm{PGE}_{2}$ was injected i.c.v. at a single dose of 1 nmole in ethanol-anaesthetized rats, urine outflow increased by about $50 \%, 10 \mathrm{~min}$ later. Then, urine outflow decreased gradually and a maximal decrease (to $85 \%$ of pre-PGE $\mathrm{PG}_{2}$ level) was observed $40-50 \mathrm{~min}$ after the injection (Fig. 1), One tenth nmoles of $\mathrm{PGE}_{2}$ produced diuresis but antidiuresis was not significantly observed. These diuretic and antidiuretic actions were not produced by intracarotid and i.v. injections of 1 nmole of $\mathrm{PGE}_{2}$ (data not shown).

When the ventricular system was perfused at the rate of $10 \mathrm{t}, \mathrm{l} / \mathrm{m}$ in with CSF containing morphine at a concentration of $0.1 \mathrm{mM}$, urine outflow decreased (Fig. 2). When this decrease in urine outflow attained a steady-state which was continued for a few hr, $\mathrm{PGE}_{2}$ was injected i.c.v. at the dose of 1 nmole. Neither the diuretic nor antidiuretic effects of 


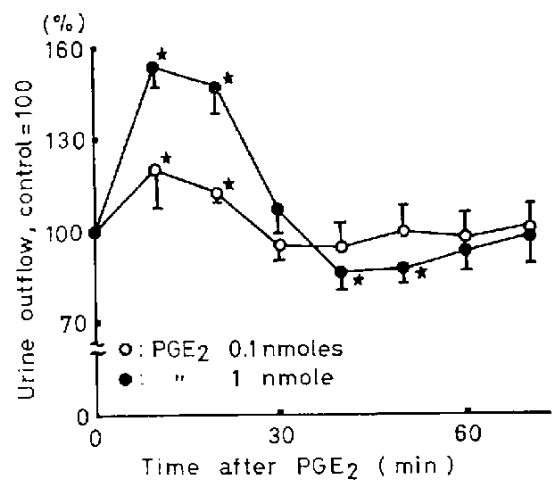

FIG. 1. Effect of i.c.v. injected $\mathrm{PGE}_{2}$ at doses of $0.1(\mathrm{)})$ and $1(0)$ nmoles on urine outflow. Abscissa: time (min) after the injection, ordinate: urine outflow (pre$\mathrm{PGE}_{2}$ level: $0.8-1.2 \mathrm{ml} / 10 \mathrm{~min}$ as $100 \%$ ). Vertical lines represent S.E. of means in $8-12$ instances. ${ }^{*} \mathrm{P}<0.05$, significant difference from the controls.

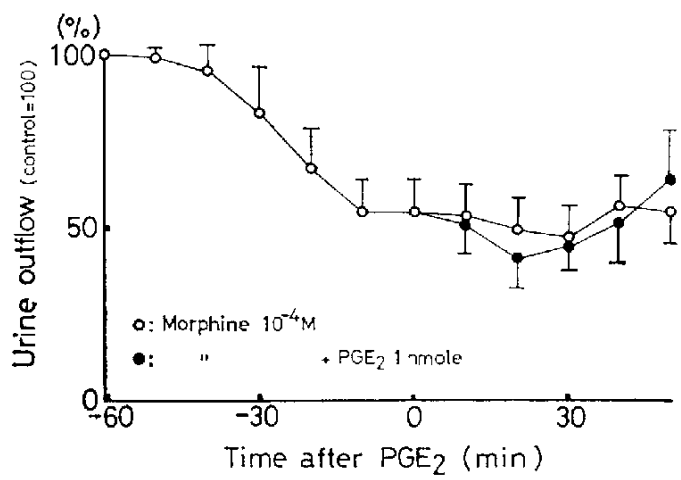

FIG. 2. Effects of i.c.v. perfused morphine $(0.1 \mathrm{mM})$ and of $\mathrm{PGE}_{2}(1 \mathrm{nmole})$ during the morphine-perfusion on urine outflow. The perfusion rate was $10 \mu \mathrm{l} / \mathrm{min}$. Abscissa: time (min) before and after the injection of $\mathrm{PGE}_{2}$, ordinate: urine outflow (premorphine level $=100 \%$ ). Morphine alone $(O), \mathrm{PGE}_{2}$ in the presence of morphine (O). Vertical lines represent S.E. of means in 8-12 instances.

$\mathrm{PGE}_{2}$ were observed in the morphine-treated group. Although the diuretic effect of $\mathrm{PGE}_{2}$ was slightly but significantly inhibited even by a smaller dose $(5 \mu \mathrm{M})$ of morphine by which urine outflow was not altered, the antidiuretic effect of $\mathrm{PGE}_{2}$ remained unchanged (data not shown).

When $\mathrm{PGE}_{2}$ (1 nmole) was injected i.c.v. 60 min after starting the i.c.v. perfusions with pentobarbital (Fig. 3, top panel), diazepam (Fig. 3, top panel), isoniazid (Fig. 3, middle panel) and strychnine (Fig. 3, middle panel) at doses of $0.1 \mathrm{mM}, 0.5 \mathrm{mM}, 20 \mu \mathrm{M}$ and $0.1 \mathrm{mM}$, respectively, the diuretic effect of $\mathrm{PGE}_{2}$ was significantly inhibited but antidiuresis in response to $\mathrm{PGE}_{2}$ remained unchanged. On the other hand, the diuretic effect of $\mathrm{PGE}_{\mathrm{a}}$ was partially inhibited and the antidiuretic effect was completely blocked, when $\mathrm{PGE}_{2}$ was injected i.c.v. at the dose of 1 nmole $60 \mathrm{~min}$ after starting the perfusion with $20 \mu \mathrm{M}$ of picrotoxin (Fig. 3 , bottom panel). The perfusion with amitriptyline at a concentration of $0.1 \mathrm{mM}$ in the 
same manner prevented completely the diuretic action of $\mathrm{PGE}_{2}$ and increased antidiuresis appeared (Fig. 3, bottom panel).

GABA and L-GA were perfused i.c.v. at rates of $0.1 \mu \mathrm{moles} / \mathrm{min}$ and $2-5$ nmoles/min, respectively, and 60 min later $\mathrm{PGE}_{2}$ was injected i.c.v. at the dose of 1 nmole. As shown in Fig. 4, these drugs inhibited partially the development of diuresis in response to $\mathrm{PGE}_{2}$ and the $\mathrm{PGE}_{2}$-induced antidiuresis did not occur during the experiments.

Control perfusions with pentobarbital, diazepam, picrotoxin, amitriptyline, GABA and L-GA at doses used did not alter the rate of urine outflow. Isoniazid alone at the dose used increased significantly urine outflow. The increase was maintained during the perfusion with the drug. Strychnine by itself at the dose used temporarily increased urine outflow.

In rats which had been treated with i.c.v. reserpine ( 49 nmoles) $24 \mathrm{hr}$ before the perfusion study was carried out, the maximal diuretic response to $\mathrm{PGE}_{2}$ was not changed but the diuretic period was extended (Fig. 5). PGE $_{2}$ increased urine outflow by $1.6 \pm 0.2$ (S.E.) $\mathrm{ml}$ for $40 \mathrm{~min}$ in the reserpine-treated group, while in the control group, $\mathrm{PGE}_{2}$ increased it by $1.1\rfloor 0.1 \mathrm{ml}$ for $30 \mathrm{~min}$. The increase in urine outflow in response to $\mathrm{PGE}_{2}$ in the reserpinized rat was significantly larger as compared with the control. Antidiuresis in response to $\mathrm{PGE}_{2}$ was not observed in the reserpinized group (Fig. 5).

As reported in a previous paper (19),

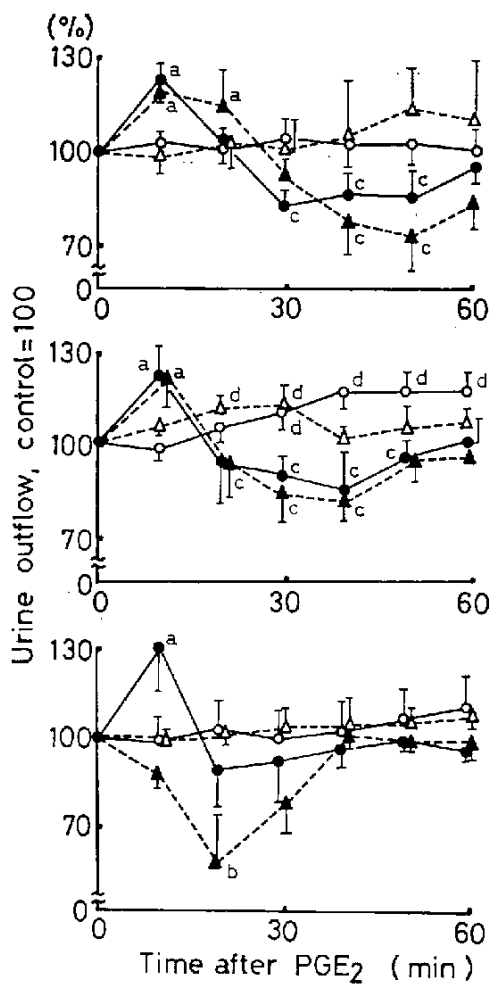

Fig. 3. Top panel; Effects of $\mathrm{PGE}_{2}$ in the presence of pentobarbital $(0.1 \mathrm{mM}, 0)$ and diazepam $(0.5 \mathrm{mM}, \mathbf{\Delta})$ on urine outflow. Pentobarbital alone $(O)$, diazepam alone $(\triangle)$. Middle panel; The effect of $\mathrm{PGE}_{2}$ in the presence of isoniazid $(20 \mu \mathrm{M}$, and strychnine $(0.1 \mathrm{mM}, \boldsymbol{\Delta})$ on urine outflow. Isoniazid alone $(O)$, strychnine alone ( $\triangle$ ). Bottom panel; The effect of $\mathrm{PGE}_{2}$ during the perfusion with picrotoxin $(20 \mu \mathrm{M}, \bigcirc)$ and amitriptyline $(0.1$ $\mathrm{mM}, \boldsymbol{A})$ on urine outflow. Picrotoxin alone $(\bigcirc)$, amitriptyline alone $(\triangle) . \quad \mathrm{PGE}_{2}$ at the dose of 1 nmole was injected at zero min (in abscissa) 60 min after starting the perfusion with the centrally acting drugs. The same legends as Fig. 1. Significant differences when compared with the diuretic $(\mathrm{a}, \mathrm{P}<0.05)$ and the maximally antidiuretic effects $(\mathrm{b}, \mathrm{P}<0.05)$ of $\mathrm{PGE}_{2}$ (1 nmole) alone and significant differences from the centrally acting drugs by themselves $(c, P<0.05)$ and from the nontreated group $(\mathrm{d}, \mathrm{P}<0.05)$.

1-norepinephrine, when injected i.c.v. at doses ranging from 1 nmole to 0.1 /moles, decreased urine outflow (Fig. 6). This antidiuresis was not varied by the pretreatment with i.c.v. reserpine. 


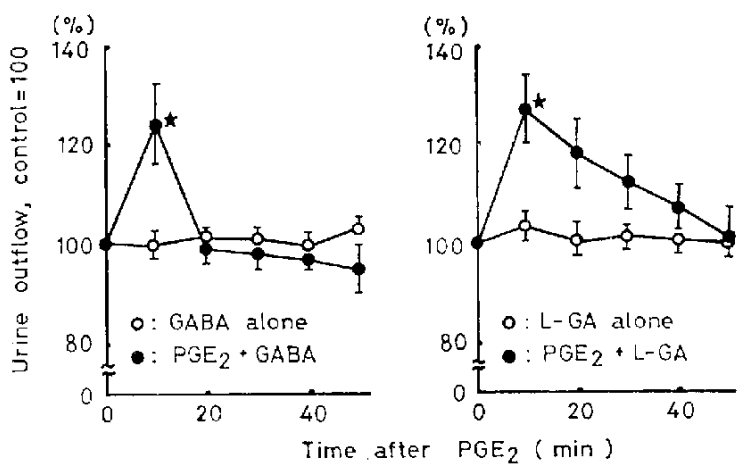

FiG. 4. Effects of $\mathrm{PGE}_{2}$ in the presence of GABA (left) and L-GA (right) on urine outflow (O). GABA and L-GA were perfused i.c.v, at the rates of 0.1 moles, min and 2.5 moles/min, respectively. GABA and L-GA by themselves ( $O$ ). See Fig. 3 for detailed explanations. $* P<0.05$, significant difference from the diuretic effect of $\mathrm{PGE}_{2}$ alonc.

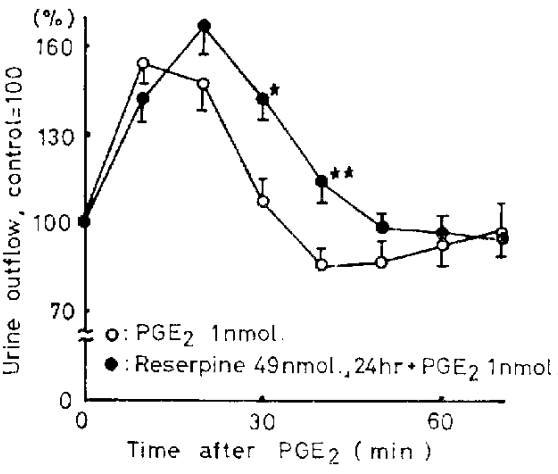

FIG. 5. Prolongation by reserpine pre-treatment of the diuretic effect of 1 nmole of PGE. Reserpine at the dose of 49 nmoles was injected i.c.v, and $24 \mathrm{hr}$ later $\mathrm{PGE}_{2}$ was injected i.c.v. (O). $\mathrm{PGE}_{2}$ in the control group ( $)$. The same legends as in Fig. 1. ${ }^{*} \mathrm{P}<0.05$, significant difference from urine outflow 30 min after the $\mathrm{PGE}_{2}$-injection in the control group, $* * P<0.05$, significant difference when compared with the pre-PGE level. $^{2}$

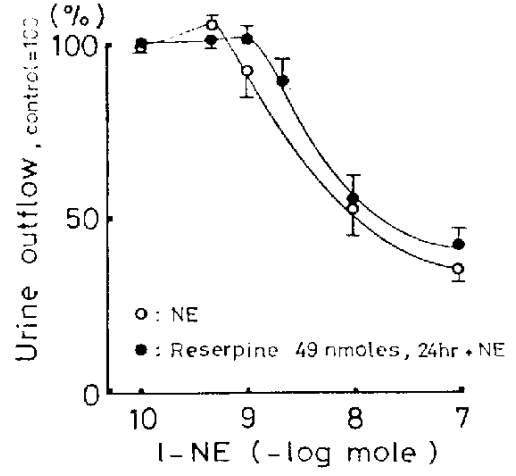

FIG. 6. The cflect of reserpine on the 1norepinephrine-induced decreasc in urine outflow. Abscissa: doses (moles) of NE. (-log scalc), ordinate: $\%$ of urine outflow to the control $(=100 \%)$. NE alone $(O), N E$ in the reserpine treated rat $(O)$. Vertical lines indicate S.E. of the mean in 8-12 instances. The dose response curve for NE which was represented in the previous paper (19) was again quoted here.

\section{DISCUSSION}

The present result that the diuretic and antidiuretic effects of i.c.v. PGE 2 were independently affected by some of drugs used, strikingly suggested that these effects were dissociated each other. The effect of $P G E_{2}$ is, therefore, a summation of both effects. The fact that injections of $\mathrm{PGE}_{2}$ at the dose of 1 nmole by i.v. and intracarotid routes did not change urine outflow in the ethanol-anaesthetized rat, suggested that i.c.v. PGE $_{2}$ at this dose could produce these effects by acting on the CNS. The hypothalamus has been proposed 
to be an action site for $\mathrm{PGE}_{1}$-induced inhibition of water diuresis (9) and $\mathrm{PGA}_{2}$-induced change in urine outflow (13). However, a more distant area of the CNS and pituitary sites cannot be ruled out. In fact, it was reported that $\mathrm{PGE}_{2}$ released $\mathrm{ADH}$ from isolated and incubated neural lobes (20-22).

Since i.c.v. injected $\mathrm{PGE}_{2}$ may affect less specifically some sites of the CNS, influence of centrally affecting drugs on the diuretic and antidiuretic effects of $\mathrm{PGE}_{2}$ was analyzed.

It was shown that i.p. morphine inhibited $\mathrm{ACTH}$ secretion evoked by $\mathrm{PGE}_{1}$ injected i.v. (14) and directly into the median eminence (15) of the pentobarbital-anaesthetized rat, suggesting that $\mathrm{PGE}_{1}$ acted on the level of the $\mathrm{CNS}$, probably the median eminence. Morphine is a drug which induces ADH secretion by acting on the CNS. In the present work, it was demonstrated that i.c.v. perfusion with morphine $(0.1 \mathrm{mM})$ caused sustained antidiuresis and inhibited both the diuretic and antidiuretic effects of $\mathrm{PGE}_{2}$ in the ethanolanaesthetized rat. Even when the smaller dose $(5 \mu \mathrm{M})$ of morphine which did not reduce urine outflow was perfused i.c.v., the diuretic but not antidiuretic effect of $\mathrm{PGE}_{2}$ was inhibited. Picrotoxin at the dose of $20, z \mathrm{M}$ was also shown to inhibit both the diuretic and antidiuretic effects of $\mathrm{PGE}_{2}$. It has been reported that the thermogenic effect of i.c.v. $\mathrm{PGE}_{2}$ at doses ranging from 10 pmoles to 0.1 , $/$ moles was inhibited by picrotoxin at doses of $20 \mu \mathrm{M}$ $0.4 \mathrm{mM}$ in rats (17).

Pentobarbital, diazepam, isoniazid and strychnine were all potent inhibitors of the diuretic effect of $\mathrm{PGE}_{2}$. However, antidiuresis in response to $\mathrm{PGE}_{2}$ remained unchanged in the presence of these drugs. Since pentobarbital does not inhibit $\mathrm{PGE}_{2}$-induced ACTH secretion (23), it is likely that mechanisms for the diuretic action of $P G E_{2}$ differ from those for the ACTH-releasing effect of PGE. Although possible interaction between $\mathrm{PGE}_{1}$ and strychnine (24) was confirmed, a further study to explain in detail interactions between PGE $_{2}$ and the centrally acting drugs was not reported.

The effect of $\mathrm{PGE}_{2}$ on urine outflow in the presence of the CNS depressants was similar to that in the presence of the convulsants. Hence, since GABA and L-GA appeared to be inhibitory and excitatory transmitters in the CNS, respectively $(25,26)$, we attempted to determine whether or not the effects of $\mathrm{PGE}_{2}$ were influenced by these drugs. We found that those compounds behaved similarly towards the diuretic and antidiuretic effects of $\mathrm{PGE}_{2}$. Thus, at least the diuretic effect of $\mathrm{PGE}_{2}$ was less specifically inhibited by various drugs. Over all, the diuretic effect of i.c.v. $\mathrm{PGE}_{2}$ might be, at least in part, due to a nonspecific action on wide-spread areas of the CNS.

Although isoniazid and strychnine at the doses used produced sustained and temporal diuresis, respectively and morphine decreased urine outflow, a further study was not done to elucidate the mechanisms of these effects. The doses of other drugs perfused would be maximal within doses which did not change urine outflow. When all of the drugs, including isoniazid, strycbnine and morphine, were perfused at doses 6-10 times as large as those used, urine outflow decreased irreversibly, and 40-80 min later, the outflow of urine stopped completely. On the other hand, when perfused at one tenth of the dose used, none of these drugs altered either the diuretic or the antidiuretic effects of $\mathrm{PGE}_{2}$. 
The antidiuretic effect of $\mathrm{PGE}_{2}$ might be mediated by adrenergic mechanisms, since amitriptyline prevented completely the development of diuresis in response to $\mathrm{PGE}_{2}$ and increased antidiuresis, and since centrally injected norepinephrine acted as antidiuretic $(19,27,28)$ and released $\operatorname{ADH}(28,29)$. The pretreatment with reserpine did not vary the antidiuretic effect of exogenous norepinephrine (Fig. 6), suggesting that the sensitivity of adrenoceptors to norepinephrine was not changed by this treatment. Reserpine increased the diuretic effect of $P G E_{2}$, but the antidiuretic effect of $\mathrm{PGE}_{2}$ was not observed in these rats. These observations suggest that amounts of norepinephrine mediating the antidiuretic effect of $\mathrm{PGE}_{2}$ were decreased by pretreatment with reserpine. Although ample experimental evidence indicates that $E$ series of the PGs might control the adrenergic neuroeffector transmission by inhibiting norepinephrine release from the periphcral nervous system (30-32), such may not be the case in the CNS.

\section{REFERENCES}

1) Holmes, S.W. And Horton, E.W.: The nature and distribution of prostaglandins in the central nervous system of the dog. J. Physiol. 191, 134P-135P (1967)

2) Holmes, S.W. aNd Horton, E.W.: The identification of four prostaglandins in dog brain and their regional distribution in the central nervous system. J. Physiol. 195, 731-740 (1968)

3) Coceant, F., Puglisi, L. And Lavers, B.: Prostaglandins and neuronal activity in spinal cord and cuneate nucleus. Ann. N. Y. Acad. Sci. 180, 289-301 (1971)

4) Feldierg, W. And Mrers, R.D.: Appearance of 5-hydroxytryptamine and an unidentified pharmacologically active lipid acid in effluent from perfused cerebral ventricles. J. Physiol. 184, 837-855 (1966)

5) Ramwell, P.W. ANd SHAw, J.E.: Spontaneous and eyoked release of prostaglandins from cerebral cortex of anesthetized cats. Am. J. Physiol. 211, 125-134 (1966)

6) Bradley, P.B., Samulls, G.M.R. and Shaw, J.E.: Correlation of prostaglandin relcase from the cerebral cortex of cats with the electrocorticogram, following stimulation of the reticular formation. Brit. J. Pharmacol. 37, 151-157 (1969)

7) Hedgr, G.A.: Roles for the prostaglandins in the regulation of anterior pituitary secretion. Life Sci. 20, 17-34 (1977)

8) Pricusky, J. ANd Deis, R.P.: Inhibitory effect of prostaglandin $F_{2,4}$ on oxytocin release and on milk ejection in lactating rats. J. Endocrinol. 69, 395-399 (1976)

9) ANdersson, W. AND LFksell, L.G.: Effects of fluid balance of intraventricular infusions of prostaglandin $\mathrm{E}_{1}$. Acta physiol. scand. 93, 286-288 (1975)

10) LeKseI.L, L.G.: Influence of prostaglandin $F_{\text {f }}$ on cerebral mechanisms involved in the control of fluid balance. Acta physiol. scand. 98, 85-93 (1976)

11) Yamamoto, M., Sharf, L. avd Shade, R.E.: Vasopressin release during ventriculo-cisternal perfusion with prostaglandin $\mathrm{E}_{2}$ in the dog. J. Endocrinol. 71, 325-331 (1976)

12) Hisada, S., Fujimoto, S., Kamiya, T., Endo, Y. and Tsusimma, H.; Release of AdH by glutamic acid analogues from the isolated neurohypophysis and their central antidiuretic action in rats. Japam. J. Pharmacol. 26 Suppl. 113P (1976)

13) Funmoto, S., Enoo, Y. Ano Hisada, S.: Centrally-mediated effects of prostaglandin $\mathrm{A}_{2}$ on urine outflow. Japan. J. Pharmacol. 27, 325-326 (1977)

14) PEng, T.C., Six, K.M. AND MUNSon, P.L.: Effects of prostaglandin $E_{1}$ on the hypothalamohypophyseal-adrenocortical axis in rat. Fndocrinology 86, 202-206 (1970)

15) Hedge, G.A. AND Hanson, S.D.: The effects of prostaglandins on ACTH secretion. Endocrinology 91, 925-933 (1972)

16) Laburn, H.P., RosendorfF, C., Willies, G. And WoOlf, C.: A role for noradrenaline and cyclic AMP in prostaglandin $\mathrm{E}_{1}$ fercr. \%. Physiol. 240, 49P-50P (1974)

17) Funmoto, S. And Hisada, S.: Inhibition by picrotoxin of thermogenic effect of centrally- 
applied prostaglandin $\mathrm{E}_{2}$ in ethanol anaesthetized rats. Japan. J. Pharmacol. 27, 611-612 (1977)

18) Fuлাмото, S.: Relative influence of anaesthetics on depressor effects of intravenous prostaglandins $\mathrm{E}_{2}$ and $\mathrm{A}_{2}$. Japan. J. Pharmacol. 27, 473-475 (1977)

19) Hisada, S., Fujmoto, S., KamiYa, T., Endo, Y. and Tsushima, H.: Antidiuresis of centrally administered amines and peptides and release of antidiuretic hormone from isolated rat neurohypophysis. Japan. J. Pharmacol. 27, 153-161 (1977)

20) Vilhardt, H. AND HedQvist, P.: A possible role of prostaglandin $E_{2}$ in the regulation of vasopressin secretion in rats. Life Sci. 9, part 1, 825-830 (1970)

21) Gagnon, D.J., Cousineau, D. And Bolcher, P.J.: Release of vasopressin by angiotensin II and prostaglandin $E_{2}$ from the rat neuro-hypophysis in vitro. Life Sci. 12, part 1, $487-497(1973)$

22) Hisada, S., Fuimoto, S., Kamya, T., Tsushima, H. and Endo, Y.: Release of antidiuretic hormone by biogenic amines, peptides and prostaglandins from the rat neurohypophysis. Japan. J. Pharmacol. 25 Suppl. 167P (1975)

23) De Wied, D., Witter, A., Verstieci, D.H.G. and Muldz r, A.H.: Release of ACTH by substances of central nervous system origin. Endocrinology 85, 561-569 (1969)

24) Duru, S. ANv TuRker, R.K. : Effect of prostaglandin $E_{1}$ on the strychnine-induced convulsion in the mouse. Experientia 25, 275 (1969)

25) Curtis, D.R. AND WATkins, J.C.: The pharmacology of amino acids related to gammaaminobutyric acid. Pharmacol. Rev. 17, 347-391 (1965)

26) Ginsborci, B.L.: Ion movements in junctional transmission. Pharmacol. Rev. 19, 289-316 (1967)

27) Olsson, K.: Effects of water diuresis of infusions of transmitter substances into the 3rd ventricle. Acta physiol. scand. 79, 133-135 (1970)

28) Bhargava, K.P., Kulshristila, V.K. and Sruvastava, Y.P.: Central cholinergic and adrenergic mechanisms in the release of antidiuretic hormone. Brit. J. Pharmacol. 44, 617-627 (1972)

29) Milton, A.S. And Paterson, A.T.: A microinjection study of the control of antidiuretic hormone release by the supraoptic nucleus of the hypothalamus in the cat. J. Physiol. 241, 607.628 (1974)

30) Hedquist, P.: Modulating effect of prostaglandin $E_{2}$ on noradrenaline release from the isolated cat spleen. Acta physiol. scand. 75, 511-512 (1969)

31) HLDQvist, P. AND Brundin, J.: Inhibition by prostaglandin $E_{1}$ of noradrenaline relcase and of effector response to nerve stimulation in the cat splecn. Life Sci. 9, part 1, 389-395 (1969)

32) Hedevist, P.: Further evidence that prostaglandins inhibit the release of noradrenaline from adrenergic nerve terminals by restriction of availability of calcium. Brit. $J$. Pharmacol. 58, 599-603 (1976) 